Portland State University

PDXScholar

\title{
Prescription Opioid Use Patterns, Use Disorder Diagnoses, and Addiction Treatment Receipt after the 2014 Medicaid Expansion in Oregon
}

\author{
Rachel Springer \\ Oregon Health \& Science University \\ Miguel Marino \\ OHSU-PSU School of Public Health, marinom@ohsu.edu \\ Steffani R. Bailey \\ Oregon Health \& Science University \\ Heather Angier \\ Oregon Health \& Science University \\ Jean O'Malley additional works at: https://pdxscholar.library.pdx.edu/sph_facpub \\ Oregon Health \& Science University \\ Part of the Community Health and Preventive Medicine Commons, and the Health Services Research \\ Commons \\ seepextrageforadditional authors
}

\section{Citation Details}

Springer, Rachel; Marino, Miguel; Bailey, Steffani R.; Angier, Heather; O'Malley, Jean; Hoopes, Megan; Lindner, Stephan; DeVoe, Jennifer E.; and Huguet, Nathalie, "Prescription Opioid Use Patterns, Use Disorder Diagnoses, and Addiction Treatment Receipt after the 2014 Medicaid Expansion in Oregon" (2019). OHSU-PSU School of Public Health Faculty Publications and Presentations. 222.

https://pdxscholar.library.pdx.edu/sph_facpub/222

This Post-Print is brought to you for free and open access. It has been accepted for inclusion in OHSU-PSU School of Public Health Faculty Publications and Presentations by an authorized administrator of PDXScholar. Please contact us if we can make this document more accessible: pdxscholar@pdx.edu. 


\section{Authors}

Rachel Springer, Miguel Marino, Steffani R. Bailey, Heather Angier, Jean O'Malley, Megan Hoopes, Stephan Lindner, Jennifer E. DeVoe, and Nathalie Huguet 
Springer Rachel (Orcid ID: 0000-0002-2633-2180)

\section{Prescription Opioid Use Patterns, Use Disorder Diagnoses, and Addiction Treatment Receipt after the 2014 Medicaid Expansion in Oregon}

Rachel Springer, $\mathrm{MS}^{\mathrm{a}, *}$, Miguel Marino, $\mathrm{PhD}^{\mathrm{a}, \mathrm{c}}$, Steffani R Bailey, $\mathrm{PhD}^{\mathrm{a}}$, Heather Angier, $\mathrm{PhD}, \mathrm{MPH}^{\mathrm{a}}$, PhD ${ }^{\mathrm{a}}$, Jean P O'Malley, MPH ${ }^{\mathrm{a}, \mathrm{b}}$, Megan Hoopes, $\mathrm{MPH}^{\mathrm{b}}$, Stephan Lindner, $\mathrm{PhD}^{\mathrm{c}, \mathrm{d}}$, Jennifer E DeVoe, MD, DPhil ${ }^{\mathrm{a}, \mathrm{b}}$, Nathalie Huguet, $\mathrm{PhD}^{\mathrm{a}}$

${ }^{a}$ Department of Family Medicine, Oregon Health \& Science University, Portland, OR USA.

${ }^{\mathrm{b}}$ OCHIN, Portland OR USA.

${ }^{c}$ School of Public Health, Oregon Health \& Science University-Portland State University, Portland, OR USA.

${ }^{\mathrm{d}}$ Center for Health Systems Effectiveness, Oregon Health \& Science University, Portland,

OR USA.

*Corresponding Author:

Rachel Springer, MS

Biostatistician

Department of Family Medicine, Mailcode: FM

Oregon Health \& Science University

3181 SW Sam Jackson Park Rd,

Portland OR 97239

springra@ohsu.edu

Abstract word count: 290

Main body of text word count: 3,405

Tables and Figures: 5

Number of references: 38

Running head: Opioid Use after the 2014 Medicaid Expansion

The authors declare no conflict of interest, financial or other, exists.

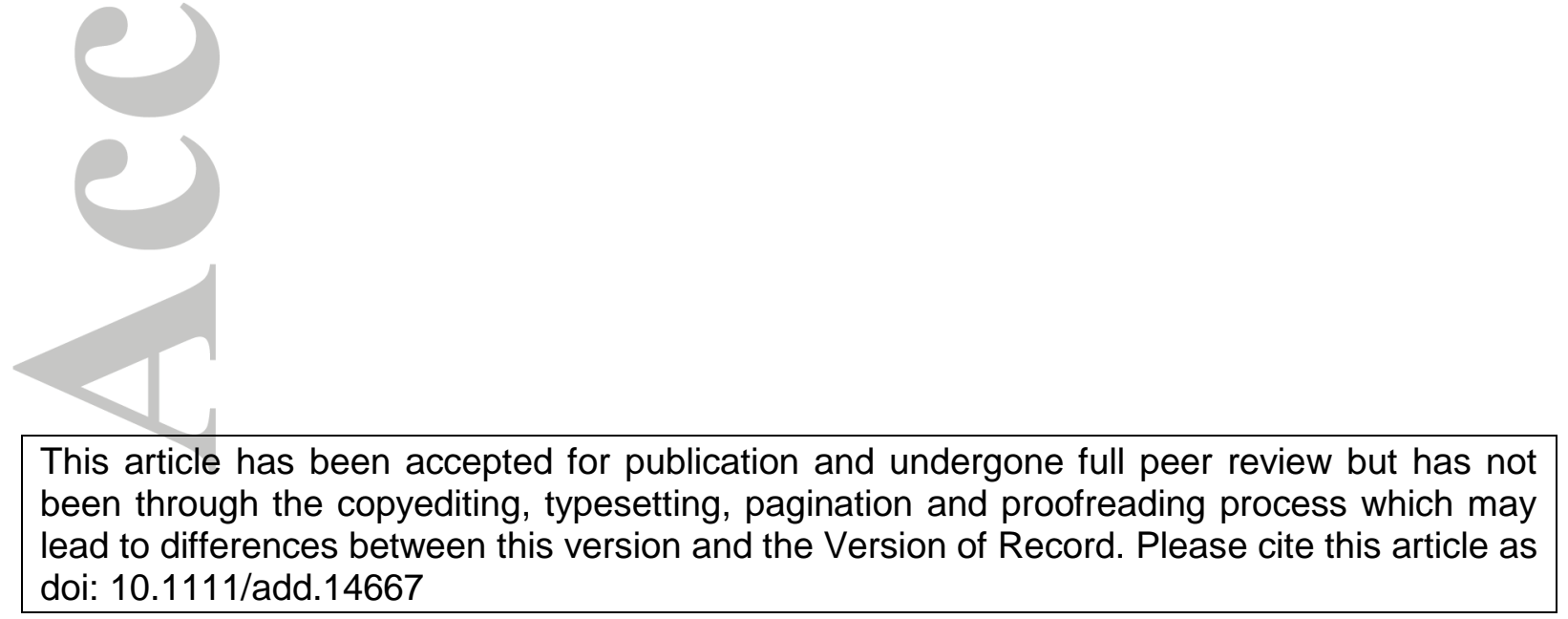




\section{ABSTRACT}

Background/Aims: Evidence suggests Medicaid beneficiaries in the USA are prescribed opioids more frequently than are people who are privately-insured, but little is known about opioid prescribing patterns among Medicaid enrollees who gained coverage via the Affordable Care Act Medicaid expansions. This study compared the prevalence of receipt of opioid prescriptions and opioid-use-disorder (OUD), along with time from OUD diagnosis to medication-assisted treatment (MAT) receipt between Oregon residents who had been continuously insured by Medicaid, were newly insured after Medicaid expansion in 2014, or returned to Medicaid coverage after expansion.

Design: Cross-sectional study using inverse-propensity weights to adjust for differences among insurance groups.

Setting: Oregon.

Participants: 225,295 Oregon Medicaid adult beneficiaries insured 2014-2015 and either: 1) newly enrolled, 2) returning in 2014 after a >12-month gap, or 3) continuously insured between 2013 and 2015. We excluded patients in hospice care or with cancer diagnoses. Measurements: Any opioid dispensed, chronic ( $\geq 90$-day) and high dose ( $\geq 90$ daily morphine milligram equivalence) opioid use, documented OUD diagnosis, and MAT receipt. Findings: Compared with the continuously insured, newly and returning insured enrollees were less likely to be dispensed opioids [newly: $42.3 \%, 95 \%$ confidence interval $(95 \% \mathrm{CI})$ 42.0-42.7\%; returning: 49.3\%, 95\%CI 48.8-49.7\%; continuously: 52.5\%, 95\%CI 52.053.0\%], use opioids chronically (newly: $12.8 \%$, 95\%CI 12.4-13.1\%; returning: $11.9 \%$, 95\% CI 11.5-12.3\%, continuously: 15.8\%, 95\%CI 15.4-16.2\%), have OUD diagnoses (newly: 3.6\%, 95\% CI 3.4-3.7\%; returning: 3.9\%, 95\% CI 3.8-4.1\%, continuously: 4.7\%, 95\%CI 4.5$4.9 \%$ ), and receive MAT after OUD diagnosis [Hazard Ratio newly: 0.57, 95\%CI 0.53-0.61; Hazard Ratio returning: 0.60, 95\%CI 0.56-0.65 (REF: continuously)].

Conclusions: Residents of Oregon, USA who enrolled or re-enrolled in Medicaid health insurance after expansion of coverage in 2014 as a result of the Affordable Care Act were less likely than those already covered to receive opioids, use them chronically, or receive medication-assisted treatment for opioid use disorder.

Keywords: Medicaid, Affordable Care Act, opioid epidemic, prescribed opioid use, opioiduse-disorder, medication-assisted treatment 


\section{INTRODUCTION AND CONTEXT}

Over the past 30 years, the role of long-term opioid therapy in managing chronic non-cancer pain has grown ${ }^{1}$, along with rates of opioid use disorder (OUD) among patients prescribed opioids $^{2}$. By 2011, the United States (US) Office of National Drug Control Policy declared opioid prescription abuse an epidemic ${ }^{3}$. Data from the US National Survey on Drug Use and Health showed that in 2016, more than $34 \%$ of individuals age 12 and older had used opioids in the prior year ${ }^{4}$. In 2016 , over 40,000 people died from an opioid overdose ${ }^{5}$. Oregon's statistics mirror national trends: From 2009 to 2014, Oregon saw a sharp increase in opioidrelated inpatient hospitalizations ${ }^{6}$, and opioid-related overdose deaths in the state increased from 2,681 deaths (death rate: 2.1 per 100,000) in 2000 to $6,535\left(6.5\right.$ per 100,000) in $2015^{7}$.

Before the 2014 Affordable Care Act (ACA) Medicaid expansion patients with Medicaid insurance were prescribed opioids at twice the rate of those without Medicaid ${ }^{8-9}$ and were on higher doses for longer periods of time ${ }^{10-11}$. Additionally, incidence of OUDs for Medicaid enrollees was about twice as high as in the general population ${ }^{12-13}$, with similar trends observed in the state of Oregon ${ }^{12}$. It is unknown, however, how opioid prescribing patterns differed between Medicaid enrollees who gained coverage from the 2014 ACA expansion and those who were previously eligible. Medicaid also provides access to medication-assisted treatment (MAT) ${ }^{13-15}$, which combines psychosocial therapy with Food and Drug Administration-approved medication. MAT is more effective in increasing treatment adherence in patients than either non-drug approaches ${ }^{16-17}$ or medication alone ${ }^{18}$, and Medicaid beneficiaries are more likely than privately-insured individuals to receive $\mathrm{MAT}^{14}$.

As a state that experienced significant increases in Medicaid enrollment in 2014 and 2015 (due to the ACA's expansion of Medicaid coverage to non-disabled adults with incomes up to 
$138 \%$ of the federal poverty level $)^{19}$ and one with increasing rates of OUD, Oregon is an excellent setting to examine opioid prescriptions and OUD treatment following the 2014 Medicaid expansion. Prior research showed that, compared with individuals previously continuously insured under Medicaid, new beneficiaries used lower levels of healthcare services in 2014 and $2015^{20}$. Furthermore, prior to the ACA expansion, the opioid epidemic had already attracted national attention in the US, and increasing awareness of the risks of opioid therapy may have influenced opioid prescribing patterns among new enrollees.

The aim of this study was to compare the prevalence of opioid prescribing, the prevalence of OUD diagnosis, and time from OUD diagnosis to MAT treatment between three insurance groups (newly, returning, and continuously insured Oregon Medicaid enrollees) following the ACA Medicaid expansion. We also sought to understand the relationship between level of chronic and high dose opioid use and prevalence of OUD diagnosis in these insurance groups.

\section{METHODS: DATA AND MEASURES}

We obtained Oregon Medicaid enrollment (01/01/2002-12/31/2015) and administrative claims $(01 / 01 / 2014-12 / 31 / 2015)$ data from the Oregon Health Authority that included both fee-for-service and managed care beneficiaries.

Study Population: We included adults aged 19-64 continuously insured by Oregon Medicaid from January 1, 2014 through December 31, 2015. To capture changes in utilization among enrolled individuals rather than changes in enrollment, we excluded patients with any coverage gaps during the study period. We also excluded patients with dual Medicaid and Medicare eligibility (as we did not have access to Medicare data) and patients whose 2014- 
2015 eligibility was not related to the Medicaid expansion (e.g. pregnant women). Finally, we excluded those in hospice care or with a cancer diagnosis other than non-melanoma skin cancer because these patients often require intense, prolonged pain management ${ }^{21}$ and are exempt from the Centers for Disease Prevention and Control (CDC) opioid prescribing guidelines $^{22}$. Of 622,513 adults aged 19-64 with any Medicaid enrollment in 2014, 225,295 $(36 \%)$ remained in our sample. See Appendix Exhibit A for a breakdown of exclusions.

Insurance Groups: We categorized patients in our study sample as newly, returning, or continuously insured:

1. Newly insured patients did not have any Medicaid coverage from 2002-2013 and had continuous coverage in 2014-2015;

2. Returning insured patients had no Medicaid coverage in 2013, had Medicaid coverage sometime during 2002-2012 and had continuous coverage in 2014-2015;

3. Continuously insured patients had Medicaid coverage for all of 2013 and continuous coverage in 2014-2015.

Episodes of Opioid Prescribing: We grouped claims for each beneficiary into 'episodes' of consecutive opioid prescriptions. Prescriptions were considered consecutive if there was no more than a 30-day gap between the end of one and the start of another ${ }^{23}$. For each episode, we calculated its length, its total day supply, and its average daily dose measured in daily morphine milligram equivalents (MME). Episode length was the number of days between the date of the first claim in the episode and the date of the last plus the day supply of the last prescription. Total day supply was the day supply summed across all claims within the episode $^{24-25}$. Average daily MME for an episode was determined by multiplying the quantity prescribed by the medication-specific strength times the conversion factor ${ }^{26}$, summing this 
value for all prescriptions within the episode, and dividing by the total day supply. If total day supply was greater than episode length, suggesting multiple concurrent prescriptions, the denominator was truncated to episode length. All episodes of opioid prescribing were categorized as low (1-30 average daily MME), medium (31-90 average daily MME), or high (>90 average daily MME). The 30 daily MME threshold was chosen because it was the median prescribed daily dose across all episodes observed ${ }^{24}$. The 90 daily MME threshold was based on CDC guidelines, which generally recommend keeping dosages below this amount $^{22}$. Other studies have chosen similar dose thresholds ${ }^{23-25}$. Finally, we summed the number of episodes experienced by each patient over the study period, operationalizing the sum as a categorical variable with 4 levels, representing 1,2,3, or 4+ prescribing episodes.

Outcomes: To assess the prevalence of opioid prescribing and OUD diagnoses among Medicaid enrollees (full sample, $n=225,295$ ), we measured:

1. Any opioid prescription filled: A binary variable indicating whether a subject filled any prescription from the CDC's published list of opioids ${ }^{26}$ (excluding buprenorphine, a partial opioid agonist used for treatment of OUD in primary care settings ${ }^{27-28}$ ) during the study period.

2. Documented diagnosis of OUD: A binary variable indicating whether a subject had a documented diagnosis of OUD, based on the presence of any international classification of diseases (ICD-9/10) codes for opioid abuse or dependence (Appendix Exhibit B1) in claims during the study period.

We also estimated the prevalence of chronic opioid use and OUD among the subset $(n=105,031)$ of Medicaid enrollees with any opioid prescription filled. We measured: 
1. Any chronic opioid use: a binary variable indicating the presence of any chronic episode, with an episode considered chronic when its length was $>90$ days and the patient was dispensed $>90$ days' supply during this period ${ }^{23-25,29}$.

2. Level of chronic opioid use: a categorical variable with five levels: i) low/medium dose non-chronic use ( $\leq 90$ average daily MME, $\leq 90$ days); ii) high dose non-chronic use (>90 average daily MME, $\leq 90$ days); iii) low dose chronic use (1-30 average daily MME, >90 days); iv) medium dose chronic use (31-90 average daily MME, >90 days), and v) high dose chronic use (>90 average daily MME, >90 days), with patients classified first based on their highest average dose chronic episode, then by whether they had any high dose use.

3. Documented diagnosis of OUD.

Among the subset of patients with OUD ( $\mathrm{n}=8,637)$, we examined time to receipt of MAT services after OUD diagnosis. Receipt of MAT services was a binary variable indicating whether a subject had any procedure codes or pharmacy national drug codes indicating $\mathrm{MAT}^{30}$ (Appendix Exhibit B2) in claims during the study period.

Independent Variables: The main independent variable was insurance group (defined above). When estimating OUD prevalence in patients with any opioid prescription, the independent variables were insurance group and episode type, representing both level of chronic use and whether they experienced a high dose episode. Episode type, a measure of length and intensity of prescribed opioid use, was operationalized as a categorical variable with the following five levels:

1. Non-chronic use and no high dose;

2. Low dose chronic use and no high dose;

3. Non-chronic or low dose chronic use and at least one high dose; 


\section{Medium dose chronic use and no high dose;}

\section{Medium or high dose chronic use and at least one high dose.}

Other Covariates: We adjusted for 'number of episodes' for all outcomes modeled in the sample of patients with any prescription (any chronic use, level of chronic use, and OUD prevalence).

\section{METHODS: STATISTICAL ANALYSES}

Propensity Score Weighting: To adjust for observable differences between the insurance groups that may have affected outcomes, we used inverse-probability of treatment weighting $(\text { IPTW })^{31}$ via the twang (toolkit for weighting and analysis of nonequivalent groups) ${ }^{32}$ package in $\mathrm{R}$ (version 3.4.0), implementing a generalized boosted model that included the patient's age, sex, racial and ethnic background, rural setting, zip-code-level poverty and unemployment percentiles, comorbidity level as assessed by the enhanced Charlson comorbidity index ${ }^{33}$, and diagnoses associated with chronic pain (see Appendix Exhibit B3 for included pain categories and ICD-9/10 codes). We produced separate sets of average treatment effect weights for the full sample, the subset of patients with any opioid prescription, and the subset with OUD. For each patient characteristic included in the propensity model, we calculated absolute standardized mean differences between insurance groups before and after weighting to assess propensity score performance; standardized differences of less than 0.10 suggest good balance ${ }^{34}$. For all data sets, we estimated effective sample sizes (ESS), the approximate number of observations under simple random sampling that would produce variation equivalent to the weighted sample, resulting from propensity score weighting. 
Parameter Estimates and Confidence Intervals (CIs): The following analyses were performed in Stata 15.1. We report point estimates and 95\% CIs on all IPTW-adjusted parameter estimates (Appendix Exhibits D1-D7) from the proposed models below.

Binary Logistic Regressions: Among the full sample, we ran IPTW binary logistic regressions to estimate the likelihood of having any opioid prescription filled and OUD diagnosis prevalence by insurance group. Among the subset of patients with any opioid prescription, we estimated the likelihood of having any chronic episode by insurance group, adjusted for number of episodes, as well as OUD diagnosis prevalence by insurance group and episode type, also adjusted for number of episodes.

Multinomial Logistic Regression: We ran an IPTW multinomial logistic regression to predict the level of chronic use (low/medium dose non-chronic use, high dose non-chronic use, low dose chronic use, medium dose chronic use, or high dose chronic use) in patients with any opioid prescription by insurance group, adjusted for number of episodes.

Cox Regression: Among the subset of patients with OUD diagnosis, we used an IPTW Cox proportional hazards model to examine the relationship between insurance group and time from OUD diagnosis to MAT. For this model, we excluded patients whose MAT receipt occurred before their first OUD diagnosis during the study period, as we were unable to determine their initial date of diagnosis (3.6\% of patients with OUD).

Additional Analyses: To address concerns of selection bias due to opioid-related deaths among the full sample, we assessed the likelihood of having experienced an overdose event 
(binary), as indicated by ICD-9/10 codes (Appendix Exhibit B4) in study period claims by insurance group using IPTW logistic regression.

\section{RESULTS}

\section{Covariate Balance between the Insurance Groups}

Full sample: Prior to weighting, the insurance groups differed on multiple demographic characteristics. Compared to returning and continuously insured enrollees, newly insured enrollees were more likely to be older, male, and Hispanic, live in an urban location, have fewer comorbidities and chronic pain-related diagnoses, and reside in zip codes with higher levels of poverty and unemployment. Balance improved for all covariates; ESS after weighting were as follows: 34,863 for continuously insured, 47,259 for returning insured, and 86,957 for newly insured, for a total ESS of 169,079 . For the distribution of covariates before and after weighting, see Table 1.

Sample with any opioid dispensed: After weighting, balance improved for all covariates and the ESS were as follows: 25,832 for continuously insured, 27,607 for returning insured, and 31,332 for newly insured. See Appendix Exhibit C1 for the distribution of covariates before and after weighting. Compared to the full sample, patients with opioid prescriptions were more likely to be older, female, and white, live in a rural location, have more comorbidities and chronic-pain related diagnoses, and reside in zip codes with higher levels of unemployment.

Sample with OUD diagnosis: After weighting, balance improved for all covariates and the ESS were as follows: 2,550 for continuously insured, 2,515 for returning insured, and 2,327 
for newly insured. See Appendix Exhibit C2 for the distribution of covariates before and after weighting. Compared to the full sample, patients with OUD diagnoses were more likely to be young, male, and white, live in an urban location, and have more comorbidities and chronic pain-related diagnoses.

\section{Outcomes}

Any opioid dispensed, any chronic opioid use, and level of chronic opioid use: Compared to the continuously insured, newly and returning insured enrollees were less likely to have any opioid dispensed, with newly insured less likely than returning insured (Table 2; Figure 1, xaxis; Appendix D1). Among patients with opioid prescriptions, the newly insured were less likely than the continuously insured to be chronic users of all types (Table 2; Appendix D2) and less likely to be dispensed either a low, medium, or high daily chronic dose (Figure 1, yaxis; Appendix D3).

OUD diagnosis and time to receipt of MAT services: Among the full sample, the continuously insured were more likely than the newly and returning insured to have an OUD diagnosis, with newly insured less likely than returning insured (Table 2; Appendix D4). Among those with an OUD diagnosis, newly insured enrollees were $43 \%$ less likely to receive MAT after OUD diagnosis than the continuously insured. Similarly, the returning insured were $40 \%$ less likely to receive MAT after OUD diagnosis than the continuously insured, with no significant differences in MAT receipt observed between newly and returning insured (Table 2; Figure 2; Appendix D5).

OUD diagnosis and episode type: Among those with any opioid dispensed, prevalence of OUD diagnosis for all insurance groups varied significantly by length and intensity of dose received during episodes. Generally, as length and intensity increased, so did prevalence of 
OUD diagnosis. Patients with medium or high dose chronic use and at least one high dose were most likely to have an OUD diagnosis. Those with neither chronic use nor high dose episodes were least likely to have an OUD diagnosis (Figure 3; Appendix D6).

Among those with any opioid dispensed, after adjusting for episode type, the newly and returning insured remained at lower odds of OUD diagnosis than the continuously insured (Table 2; Appendix D7).

Additional analysis of overdose events: Among the full sample, less than half of a percent of patients with any prescribed opioid use experienced an overdose event. The continuously insured were slightly less likely than the newly and returning insured to have experienced an overdose event, with newly and returning insured similarly likely (Appendix D8).

This study evaluated the relationship between insurance group (newly, returning and continuously insured enrollees) and opioid prescriptions, OUD diagnoses, and MAT receipt among Oregon Medicaid beneficiaries after the ACA Medicaid expansion. We found that $42 \%$ of newly insured enrollees filled at least one prescription during the two-year study period, with estimates for returning (49\%) and continuously insured enrollees (53\%) reflecting even higher prevalences.

Among those with opioid prescriptions, relative to the continuously insured, the newly and returning insured were less likely to be chronic opioid users. This suggests that policies to decrease opioid prescribing in recent years ${ }^{35}$ may be having their desired effect on the population of newly and returning Medicaid enrollees (in contrast with the continuously insured, who may face understandable difficulties in discontinuing long-term opioid therapy). However, differing levels of chronic and high dose opioid use may be, in part, a result of 
unobserved differences in characteristics between the three groups that we were unable to control for.

Confirming other studies ${ }^{24,37}$, we found prescribed dose and duration were both significant predictors of OUD diagnosis prevalence. Patients with medium or high dose chronic use and at least one high daily dose were roughly five times more likely to be diagnosed with OUD than those with neither chronic nor high daily dose use. Since the continuously insured were more likely to be dispensed higher doses for longer periods, the continuously insured were most likely to be diagnosed with OUD. But even after adjusting for the number of prescribing episodes and level of chronic and high dose use, the continuously insured were more likely than the newly or returning insured to have OUD diagnoses. This may be because continuously insured patients had more opportunities to receive diagnoses than new enrollees. It is also possible that individuals with existing drug dependence issues were more likely to have been continuously insured, being motivated to maintain their prescribed treatment regimens.

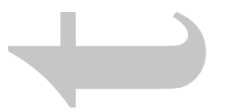

In addition to being more likely to be diagnosed with OUD, the continuously insured, if diagnosed, were more likely to receive MAT, possibly due to having had access to addiction treatment resources for longer. With greater access to care, these patients likely had more opportunities to initiate MAT. The length of the study period (24 months) may not have been sufficient to see comparable access to MAT among newly and returning insured enrollees. Additionally, there is evidence of a gap between treatment demand and MAT capacity, which may have impacted the newly and returning insured more than the continuously insured ${ }^{38}$. Thus, future research assessing long term MAT trends and capacity is necessary. 
This study had limitations. Claims data did not capture self-paid prescriptions or opioids obtained through diversion. Although we adjusted for comorbidity level and chronic pain type, we were not able to measure the severity of pain experienced by patients. We were unable to determine an initial date of diagnosis for a small percent of patients with MAT before OUD diagnosis (3.6\% of the sample with OUD). We were also unable to assess continuity of care by insurance status, which could impact OUD diagnosis and MAT receipt. Importantly, our data was limited to Oregon Medicaid claims and enrollment files, so we do not know if newly and returning Medicaid enrollees had other insurance (e.g. private insurance or Medicaid from another state) before 2014. Our exclusion of patients with cancer diagnosis (other than non-malignant skin cancer) may have removed cancer survivors who are not in active treatment. Our data did not have information on cancer stage and thus we were unable to identify these potential survivors to include in our analyses. Additionally, we were unable to identify enrollees who died and this may have contributed to beneficiaries with any coverage gaps during the study period being excluded; however, in our examination of enrollees with a diagnosis code indicating opioid overdose (unknown if fatal or non-fatal), we observed that less than half of a percent of patients with any prescribed opioid use experienced an overdose event. Because this percent was low and similar between insurance groups, potential for selection bias is minimal. Finally, our sample was limited to Oregon Medicaid enrollees and was not nationally representative.

\section{CONCLUSION}

Medicaid plays an important role in fighting the opioid epidemic: for low-income individuals who struggle with addiction, it is often the only affordable option for getting appropriate treatment. Opioid use in newly and returning insured enrollees after the ACA Medicaid 
expansion was lower than in the continuously insured, possibly reflecting lower prescribing rates combined with difficulties in discontinuing opioids in long-term users with more stable insurance coverage; however, prescribing remains high. Lower likelihood of MAT among newly and returning insured patients with OUD relative to continuously insured patients with OUD suggests that newly eligible enrollees may not yet have established the continuity of care often needed for MAT; alternately, they may have prioritized competing healthcare needs. It is essential, therefore, that policymakers consider the importance of Medicaid continuity and primary care continuity in combating the opioid epidemic and that they continue to provide adequate access to continuous insurance.

\section{ACKNOWLEDGEMENTS}

We thank the Oregon Health Authority for providing the Medicaid data used in this analysis.

This work was supported by the Agency for Healthcare Research and Quality (AHRQ), grant number R01HS024270 and by the National Cancer Institutes (NCI) grant numbers R01CA204267 and R01CA181452. 


\section{REFERENCES}

1. Gilson AM, Ryan KM, Joranson DE, et al. A reassessment of trends in the medical use and abuse of opioid analgesics and implications for diversion control: 1997-2002. Journal of Pain and Symptom Management. 2004. 28(2):176-188.

2. Compton WM, Volkow ND. Major increases in opioid analgesic abuse in the United States: concerns and strategies. Drug and Alcohol Dependence. 2006. 81(2):103-107.

3. Office of National Drug Control Policy. Epidemic: responding to America's prescription drug abuse crisis. 2001. URL:

http://publications.iowa.gov/12965/1/NationalRxAbusePlan2011.pdf (Archived by WebCite® at http://www.webcitation.org/78B84QUGS).

4. Substance Abuse and Mental Health Services Administration. Results from the 2016 National Survey on Drug Use and Health: Detailed Tables. URL:

https://www.samhsa.gov/data/sites/default/files/NSDUH-DetTabs-2016/NSDUH-DetTabs2016.pdf (Archived by WebCite® at http://www.webcitation.org/78B8UeFhw)

5. U.S. Department of Health and Human Services Fact Sheet. What is the U.S. Opioid Epidemic? URL: https://www.hhs.gov/opioids/about-the-epidemic/index.html (Archived by WebCite ${ }^{\circledR}$ at http://www.webcitation.org/78B8kJ26i)

6. Weiss A, Elixhauser A, Barrett M, et al. Opioid-Related Inpatient Stays and Emergency Department Visits by State, 2009-2014. Healthcare Cost and Utilization Project. December 2016. Statistical Brief \#219. URL: https://www.hcup-us.ahrq.gov/reports/statbriefs/sb219Opioid-Hospital-Stays-ED-Visits-by-State.jsp (Archived by WebCite ${ }^{\circledR}$ at http://www.webcitation.org/78B99uGqZ)

7. Oregon Health Authority. Prescribing and Overdose Data for Oregon: Opioid Data Dashboard. URL: https://www.oregon.gov/oha/ph/preventionwellness/substanceuse/opioids/pages/data.aspx (Archived by WebCite ${ }^{\circledR}$ at http://www.webcitation.org/78B9n9OFL)

8. Sharp MJ, Melnik TA. Poisoning deaths involving opioid analgesics-New York State, 20032012. Morb Mortal Wkly Rep. 2015. 64:377-380.

9. Coolen P, Lima A, Savel J, et al. Overdose deaths involving prescription opioids among Medicaid enrollees-Washington, 2004-2007. Morb Mortal Wkly Rep. 2009. 58:1171-1175.

10. Kim H, Hartung D, Jacob L, et al. The Concentration of Opioid Prescriptions by Providers and Patients in the Oregon Medicaid Program. Psychiatric services (Washington, DC). 2016. 67(4):397-404.

11. Heins S, Sorbero M, Jones C, et al. High-Risk Prescribing to Medicaid Enrollees Receiving Opioid Analgesics: Individual and County-Level Factors. Substance Use \& Misuse. 2018. 53(10):1591-1601.

12. Davenport S, Matthews K. Opioid use disorder in the United States: Diagnosed prevalence by payer, age, sex, and state. Milliman white paper. March 2018. URL:

http://www.milliman.com/insight/2018/Opioid-use-disorder-in-the-United-States-Diagnosedprevalence-by-payer--age--sex--and-state/ (Archived by WebCite ${ }^{\circledR}$ at http://www.webcitation.org/78BA2m4eQ)

13. MACPAC issue brief. Medicaid and the Opioid Epidemic. June 2017. URL: https://www.macpac.gov/publication/medicaid-and-the-opioid-epidemic/ (Archived by WebCite ${ }^{\circledR}$ at http://www.webcitation.org/78BAL0QJS)

14. Wen LS, Behrle EB, Tsai AC. Evaluating the impact of Affordable Care Act repeal on America's opioid epidemic. PloS Medicine. 2017. 14(8):e1002380.

15. Zur J, Tolbert J. The Opioid Epidemic and Medicaid's Role in Facilitating Access to Treatment. Kaiser Family Foundation issue brief. April 2018. URL: https://www.kff.org/medicaid/issue-brief/the-opioid-epidemic-and-medicaids-role-in- 
facilitating-access-to-treatment/ (Archived by WebCite ${ }^{\circledR}$ at http://www.webcitation.org/78BVLVTzv)

16. Mattick RP, Breen C, Kimber J, et al. Methadone maintenance therapy versus no opioid replacement therapy for opioid dependence. Cochrane Database of Systematic Reviews. 2009. 3: CD002209.

17. Fudala PJ, Bridge TP, Herbert S, et al. Office-based treatment of opiate addiction with a sublingual-tablet formation of buprenorphine and naloxone. New England Journal of Medicine. 2003. 349(10):949-958.

18. American Society of Addiction Medicine. The ASAM National Practice Guideline for the Use of Medications in the Treatment of Addiction Involving Opioid Use. 2015. URL: http://www.asam.org/docs/default-source/practice-support/guidelines-and-consensusdocs/asam-national-practice-guideline-supplement.pdf?sfvrsn=24 (Archived by WebCite ${ }^{\circledR}$ at http://www.webcitation.org/78BVsGEaS)

19. Collins J. Oregon's Health System Transformation: CCO Metrics 2015 Final Report. Oregon Health Authority. June 2016. URL: http://www.oregon.gov/oha/HPA/ANALYTICSMTX/Documents/CCO-Metrics-2015-Final-Report.pdf (Archived by WebCite ${ }^{\circledR}$ at http://www.webcitation.org/78BWKrjbl)

20. Springer R, Marino M, O’Malley J, et al. Oregon Medicaid Expenditures after the 2014 Affordable Care Act Medicaid Expansion: Over-time Differences among New, Returning, and Continuously Insured Enrollees. Medical Care. 2018. 56(5):394-402.

21. Portenoy R. Treatment of cancer pain. The Lancet. 2011. 377(9784):2236-2247.

22. Dowell D, Haegerich TM, Chou R. CDC Guideline for Prescribing Opioids for Chronic Pain -United States, 2016. MMWR Recommendations and Reports. 2016. 65(1):1-49.

23. Scherrer J, Salas J, Copeland L, et al. Prescription Opioid Duration, Dose, and Increased Risk of Depression in 3 Large Patient Populations. Annals of Family Medicine. 2016. 14(1):54-62.

24. Edlund MJ, Martin BC, Russo JE, et al. The role of opioid prescription in incident opioid abuse and dependence among individuals with chronic noncancer pain. The Clinical Journal of Pain. 2014. 30(7):557-564.

25. Centers for Medicare \& Medicaid Service. Analysis of Proposed Opioid Overutilization Criteria Modifications in Medicare Part D. February 2017. URL:

https://www.cms.gov/Medicare/Prescription-DrugCoverage/PrescriptionDrugCovContra/Downloads/Revised-OMS-Criteria-ModificationAnalysis.pdf (Archived by WebCite® at http://www.webcitation.org/78BWxc0Ua)

26. National Center for Injury Prevention and Control. Compilation of benzodiazepines, muscle relaxants, stimulants, zolpidem, and opioid analgesics with oral morphine milligram equivalent conversion factors, 2017 version. Atlanta, GA: Centers for Disease Control and Prevention; 2017. URL: https://www.cdc.gov/drugoverdose/resources/data.html (Archived by WebCite ${ }^{\circledR}$ at http://www.webcitation.org/78BXEUYNE)

27. Sigmon SC, Dunn KE, Saulsgiver K, et al. A Randomized, Double-blind Evaluation of Buprenorphine Taper Duration in Primary Prescription Opioid Abusers. JAMA Psychiatry. 2013. 70(12): 1347.

28. Fingerhood MI, King VL, Brooner RK, et al. A comparison of characteristics and outcomes of opioid-dependent patients initiating office-based buprenorphine or methadone maintenance treatment. Substance Abuse. 2014; 35(2):122-126.

29. Von Korff M, Saunders K, Thomas Ray G, et al. De facto long-term opioid therapy for noncancer pain. Clin J Pain 2008; 24:521-7.

30. Tri-County Opioid Safety Coalition Data Brief. December 2017. URL:

https://portlandprofessional.oregonpainguidance.org/wpcontent/uploads/sites/8/2017/12/MAT-Dec-2017.pdf (Archived by WebCite® at http://www.webcitation.org/78BXWS0ZV) 
31. McCaffrey D, Griffin B, Almirall D, et al. A Tutorial on Propensity Score Estimation for Multiple Treatments Using Generalized Boosted Models. Statistics in medicine. 2013; 32(19):3388-3414.

32. Charlson M, Charlson R, Peterson J, et al. The Charlson comorbidity index is adapted to predict costs of chronic disease in patients. J Clin Epidemiol. 2008. 61(12):1234-1240.

33. Ridgeway G, McCaffrey D, Morral A, et al. twang: Toolkit for Weighting and Analysis of Nonequivalent Groups. R package version 1.5. 2007.

34. Austin, P. C. (2009). Using the standardized difference to compare the prevalence of a binary variable between two groups in observational research. Communications in StatisticsSimulation and Computation, 38(6):1228-1234.

35. McCarty D, Bovett R, Burns T, et al. Oregon's Strategy to Confront Prescription Opioid Misuse: A Case Study. Journal of Substance Abuse Treatment. 2015. 48(1):91-95.

36. Health Evidence Review Commission. Prioritization of Health Services: A Report to the Governor and the $78^{\text {th }}$ Oregon Legislative Assembly. Oregon Health Authority. 2015. URL: https://www.oregon.gov/oha/HPA/DSI-HERC/Pages/Reports.aspx (Archived by WebCite ${ }^{\circ}$ at http://www.webcitation.org/78BXxkD8n)

37. Chou R, Turner JA, Devine EB, et al. The effectiveness and risks of long-term opioid therapy for chronic pain: a systematic review for a National Institutes of Health Pathways to Prevention Workshop. Annals of Internal Medicine. 2015. 162:276-286.

38. Meinhofer A, Witman A. The role of health insurance on treatment for opioid use disorders: Evidence from the Affordable Care Act Medicaid expansion. Journal of Health Economics. 2018. 60:177-197.

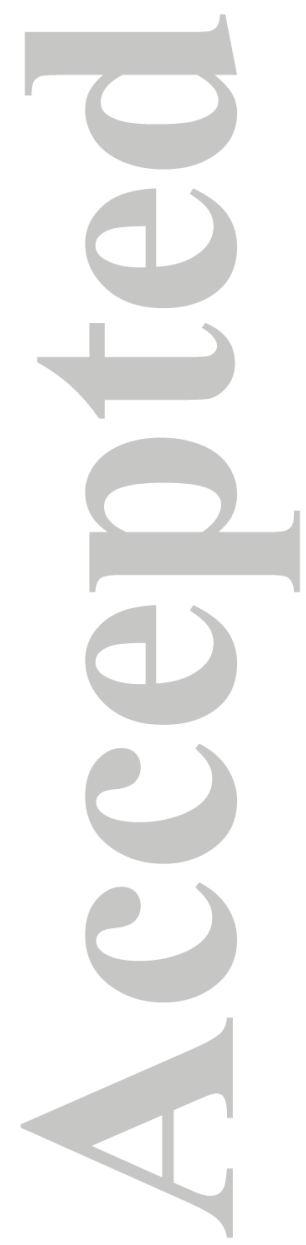


Table 1: Characteristics of newly, returning, and continuously insured enrollees (full sample).

\begin{tabular}{|c|c|c|c|c|c|c|c|c|}
\hline & \multicolumn{4}{|c|}{ Unweighted Sample, \% } & \multicolumn{4}{|c|}{ Inverse Propensity Weighted Sample, \% } \\
\hline & $\begin{array}{l}\text { Newly } \\
\text { Insured }\end{array}$ & $\begin{array}{l}\text { Returning } \\
\text { Insured }\end{array}$ & $\begin{array}{c}\text { Cont. } \\
\text { Insured }\end{array}$ & $\begin{array}{c}\operatorname{Max}^{1} \\
\text { ASMD }\end{array}$ & $\begin{array}{l}\text { Newly } \\
\text { Insured }\end{array}$ & $\begin{array}{l}\text { Returning } \\
\text { Insured }\end{array}$ & $\begin{array}{l}\text { Cont. } \\
\text { Insured }\end{array}$ & $\begin{array}{r}\text { Max }^{1} \\
\text { ASMD }\end{array}$ \\
\hline Total N|ESS & 108,501 & 59,811 & 56,983 & & 86,957 & 47,259 & 34,863 & \\
\hline \multicolumn{9}{|l|}{ Age group } \\
\hline $19-29$ & 23.3 & 31.6 & 32.4 & 0.1942 & 27.8 & 27.8 & 27.7 & 0.0033 \\
\hline $30-39$ & 22.2 & 26.0 & 29.3 & 0.1582 & 25.0 & 25.0 & 25.0 & 0.0005 \\
\hline $40-64$ & 54.5 & 42.4 & 38.4 & 0.3286 & 47.3 & 47.2 & 47.4 & 0.0036 \\
\hline Female & 44.4 & 53.9 & 67.9 & 0.4827 & 52.8 & 53.0 & 53.0 & 0.0048 \\
\hline \multicolumn{9}{|l|}{ Race/Ethnicity } \\
\hline Hispanic & 16.0 & 14.7 & 9.0 & 0.218 & 13.9 & 13.9 & 13.8 & 0.0033 \\
\hline Non-Hisp. Non-White & 8.8 & 9.7 & 8.7 & 0.0342 & 9.1 & 9.1 & 9.0 & 0.0022 \\
\hline Non-Hisp. White & 51.9 & 69.6 & 75.5 & 0.5274 & 62.6 & 63.0 & 63.2 & 0.0148 \\
\hline Non-Hisp. Unknown & 23.3 & 6.0 & 6.8 & 0.7061 & 14.5 & 14.0 & 13.9 & 0.0218 \\
\hline Rural Setting ${ }^{2}$ & 36.4 & 41.5 & 41.7 & 0.106 & 39.2 & 39.2 & 39.4 & 0.0042 \\
\hline \multicolumn{9}{|l|}{ ZCTA ${ }^{3}$ Unemployment $\%$} \\
\hline $0-8.09$ & 29.5 & 21.9 & 20.5 & 0.2204 & 25.2 & 24.9 & 24.7 & 0.011 \\
\hline $8.09-9.58$ & 25.5 & 24.2 & 24.0 & 0.035 & 24.8 & 24.9 & 24.8 & 0.0029 \\
\hline $9.58-11.56$ & 23.2 & 26.4 & 27.3 & 0.093 & 25.1 & 25.2 & 25.3 & 0.0037 \\
\hline $11.56-38.84$ & 21.7 & 27.4 & 28.1 & 0.1435 & 24.8 & 24.9 & 25.1 & 0.0068 \\
\hline Unknown & 0.1 & 0.1 & 0.0 & 0.0186 & 0.1 & 0.1 & 0.1 & 0.0088 \\
\hline \multicolumn{9}{|l|}{ ZCTA ${ }^{3}$ Poverty $\%$} \\
\hline $0-13.0$ & 27.9 & 22.4 & 22.4 & 0.1321 & 25.1 & 25.0 & 25.0 & 0.002 \\
\hline $13.0-17.0$ & 26.4 & 25.1 & 23.8 & 0.0607 & 25.3 & 25.1 & 25.1 & 0.0044 \\
\hline $17.0-22.6$ & 23.9 & 26.3 & 27.6 & 0.0814 & 25.4 & 25.5 & 25.5 & 0.0025 \\
\hline $22.6-100$ & 21.8 & 26.2 & 26.3 & 0.1033 & 24.1 & 24.3 & 24.3 & 0.0043 \\
\hline Unknown & 0.1 & 0.1 & 0.0 & 0.0206 & 0.1 & 0.1 & 0.0 & 0.0096 \\
\hline \multicolumn{9}{|l|}{ Co-Morbidity Index 4} \\
\hline 0 & 45.5 & 37.1 & 31.0 & 0.3052 & 39.6 & 39.4 & 39.3 & 0.0061 \\
\hline 1 to 2 & 20.4 & 17.4 & 20.9 & 0.0885 & 19.7 & 19.7 & 19.7 & 0.0019 \\
\hline 3 to 4 & 19.3 & 25.2 & 24.9 & 0.1351 & 22.2 & 22.4 & 22.4 & 0.0046 \\
\hline 5 to 6 & 9.2 & 12.4 & 13.5 & 0.1279 & 11.1 & 11.2 & 11.2 & 0.0014 \\
\hline $7+$ & 5.7 & 7.9 & 9.8 & 0.1422 & 7.4 & 7.4 & 7.4 & 0.0012 \\
\hline Migraine & 4.6 & 6.8 & 10.7 & 0.2422 & 6.8 & 6.8 & 6.8 & 0.0014 \\
\hline Joint Pain & 36.5 & 42.1 & 49.0 & 0.2533 & 41.2 & 41.3 & 41.4 & 0.0041 \\
\hline Osteoarthritis & 8.8 & 8.6 & 10.0 & 0.0499 & 9.1 & 9.1 & 9.1 & 0.0011 \\
\hline Back Pain & 24.6 & 30.6 & 38.5 & 0.306 & 29.7 & 29.9 & 29.8 & 0.0048 \\
\hline General Chronic Pain & 8.4 & 11.1 & 15.8 & 0.2363 & 11.2 & 11.1 & 11.2 & 0.0021 \\
\hline
\end{tabular}


Table 2: Inverse-Probability of Treatment Weighted Sample Adjusted Regression Results

\begin{tabular}{|c|c|c|c|c|}
\hline Outcome & Insurance group & $\begin{array}{l}\text { Additional } \\
\text { covariates }\end{array}$ & $\begin{array}{l}\text { Adjusted } \\
\text { Estimate }\end{array}$ & $95 \% \mathrm{CI}$ \\
\hline \multirow{3}{*}{$\begin{array}{l}\text { \% Patients with any } \\
\text { opioid dispensed }{ }^{1} \text { (full } \\
\text { sample) }\end{array}$} & Newly insured & & $42.3 \%$ & $42.0-42.7 \%$ \\
\hline & Returning insured & & $49.3 \%$ & $48.8-49.7 \%$ \\
\hline & Continuously insured & & $52.5 \%$ & $52.0-53.0 \%$ \\
\hline \multirow{3}{*}{$\begin{array}{l}\text { \% Patients with chronic } \\
\text { opioid use }^{1} \text { (sample with } \\
\text { any opioid dispensed) }\end{array}$} & Newly insured & \multirow{3}{*}{$\begin{array}{l}\text { Number of } \\
\text { episodes }\end{array}$} & $12.8 \%$ & $12.4-13.1 \%$ \\
\hline & Returning insured & & $11.9 \%$ & $11.5-12.3 \%$ \\
\hline & Continuously insured & & $15.8 \%$ & $15.4-16.2 \%$ \\
\hline \multirow{3}{*}{$\begin{array}{l}\text { \% Patients with OUD } \\
\text { diagnosis }^{1} \text { (full sample) }\end{array}$} & Newly insured & & $3.6 \%$ & $3.4-3.7 \%$ \\
\hline & Returning insured & & $3.9 \%$ & $3.8-4.1 \%$ \\
\hline & Continuously insured & & $4.7 \%$ & $4.5-4.9 \%$ \\
\hline \multirow{2}{*}{$\begin{array}{l}\text { Hazard Ratio, MAT } \\
\text { receipt (sample with } \\
\text { OUD diagnosis) }\end{array}$} & $\begin{array}{l}\text { Newly insured (REF: Continuously } \\
\text { insured) }\end{array}$ & & 0.57 & $0.53-0.61$ \\
\hline & $\begin{array}{l}\text { Returning insured (REF: } \\
\text { Continuously insured) }\end{array}$ & & 0.60 & $0.56-0.65$ \\
\hline \multirow{2}{*}{$\begin{array}{l}\text { Odds Ratio, OUD } \\
\text { diagnosis }{ }^{1} \text { (sample with } \\
\text { any opioid dispensed) }\end{array}$} & $\begin{array}{l}\text { Newly insured (REF: Continuously } \\
\text { insured) }\end{array}$ & \multirow{2}{*}{$\begin{array}{l}\text { Episode type, } \\
\text { number of } \\
\text { episodes }\end{array}$} & 0.85 & $0.80-0.92$ \\
\hline & $\begin{array}{l}\text { Returning insured (REF: } \\
\text { Continuously insured) }\end{array}$ & & 0.91 & $0.85-0.98$ \\
\hline
\end{tabular}

Note: These are a selected sample of regression results. See Appendix D for all regression results.

${ }^{1}$ Results from an IPT-weighted binary logistic regression model

${ }^{2}$ Results from an IPT-weighted Cox proportional hazards model

$\mathrm{CI}=$ confidence interval

OUD $=$ opioid-use-disorder

MAT $=$ medication-assisted treatment 
Figure 1: Percent of any opioid prescribing in the overall sample and percent of low dose chronic use, medium dose chronic use, high dose non-chronic use, and high dose chronic use among patients with any opioid prescription by insurance group.

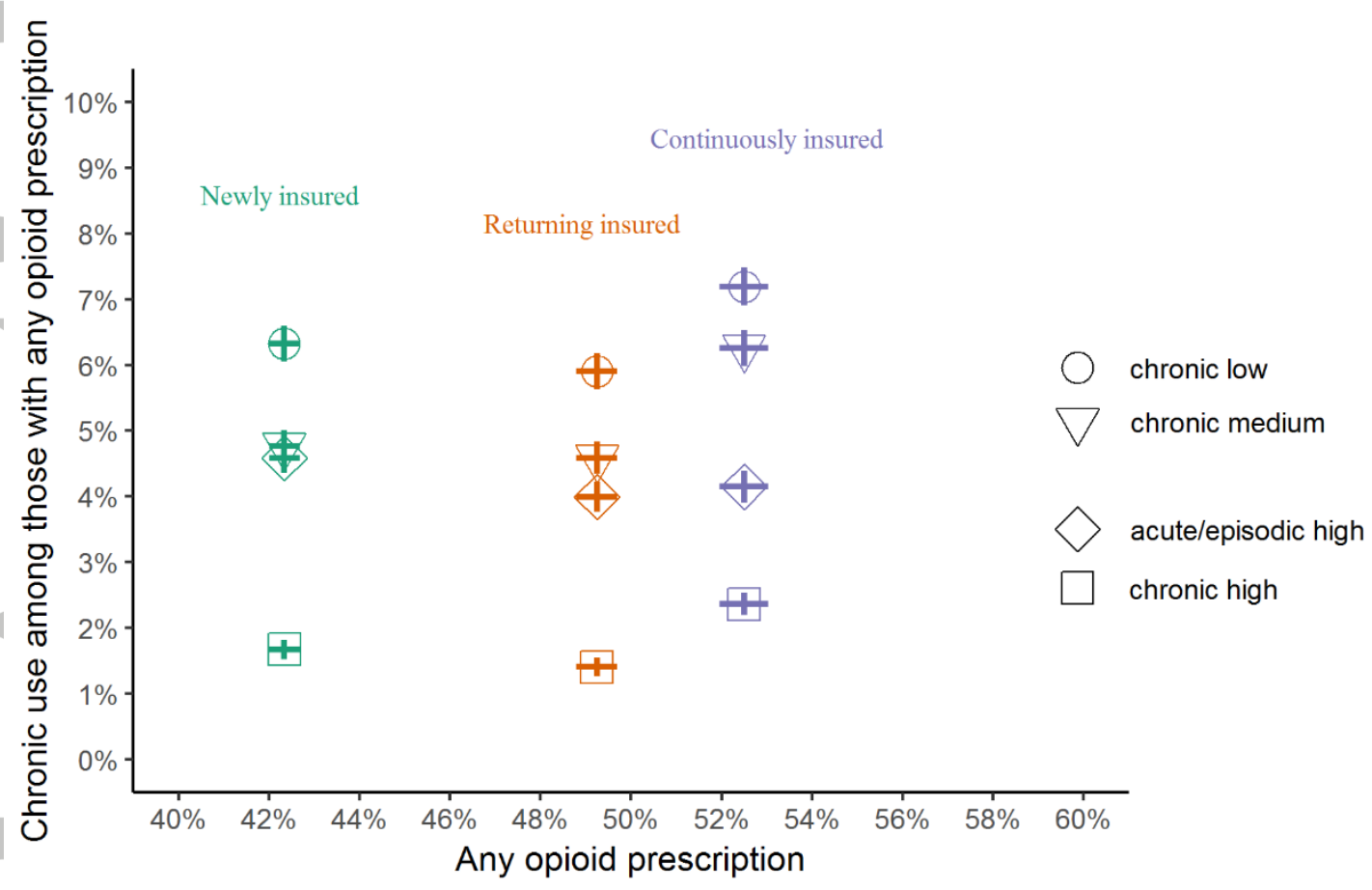

Chronic low: 1-30 average daily MME, $>90$ days

Chronic medium: 31-90 average daily MME, $>90$ days

Chronic high: $>90$ average daily MME, $>90$ days

Non-chronic high: $>90$ average daily MME, $\leq 90$ days

Opioids prescribed in our sample included butorphanol, codeine, fentanyl, hydrocodone, hydromorphone, levorphanol, meperidine, methadone, morphine, opium, oxycodone, oxymorphone, pentazocine, tapentadol, and tramadol.

Horizontal bars indicate $95 \%$ confidence intervals for likelihood of any opioid prescription; vertical bars indicate $95 \%$ confidence intervals chronic low, chronic medium, and chronic high opioid use. These estimates and confidence intervals were produced using binary and multinomial logistic models incorporating inverse-probability of treatment weights. 
Figure 2: IPT-weighted Kaplan-Meier estimates of MAT receipt among patients with OUD by insurance group.

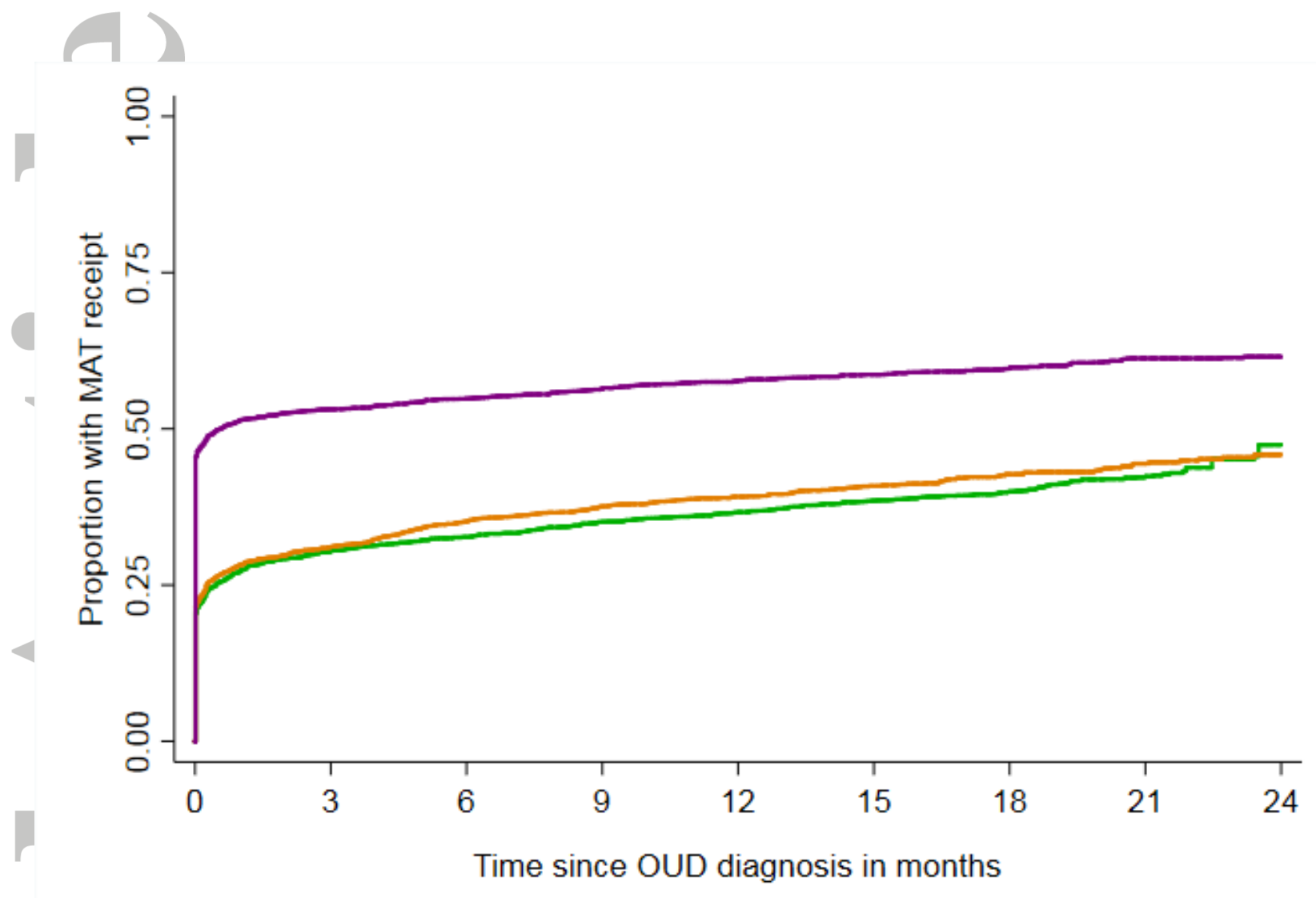

Newly Insured

Returning Insured-

Continuously Insured

IPT $=$ inverse-probability of treatment

OUD $=$ opioid-use-disorder

MAT $=$ medication-assisted treatment 
Figure 3: Percent of opioid-use-disorder diagnosis by episode type and insurance group among patients with any opioid prescription

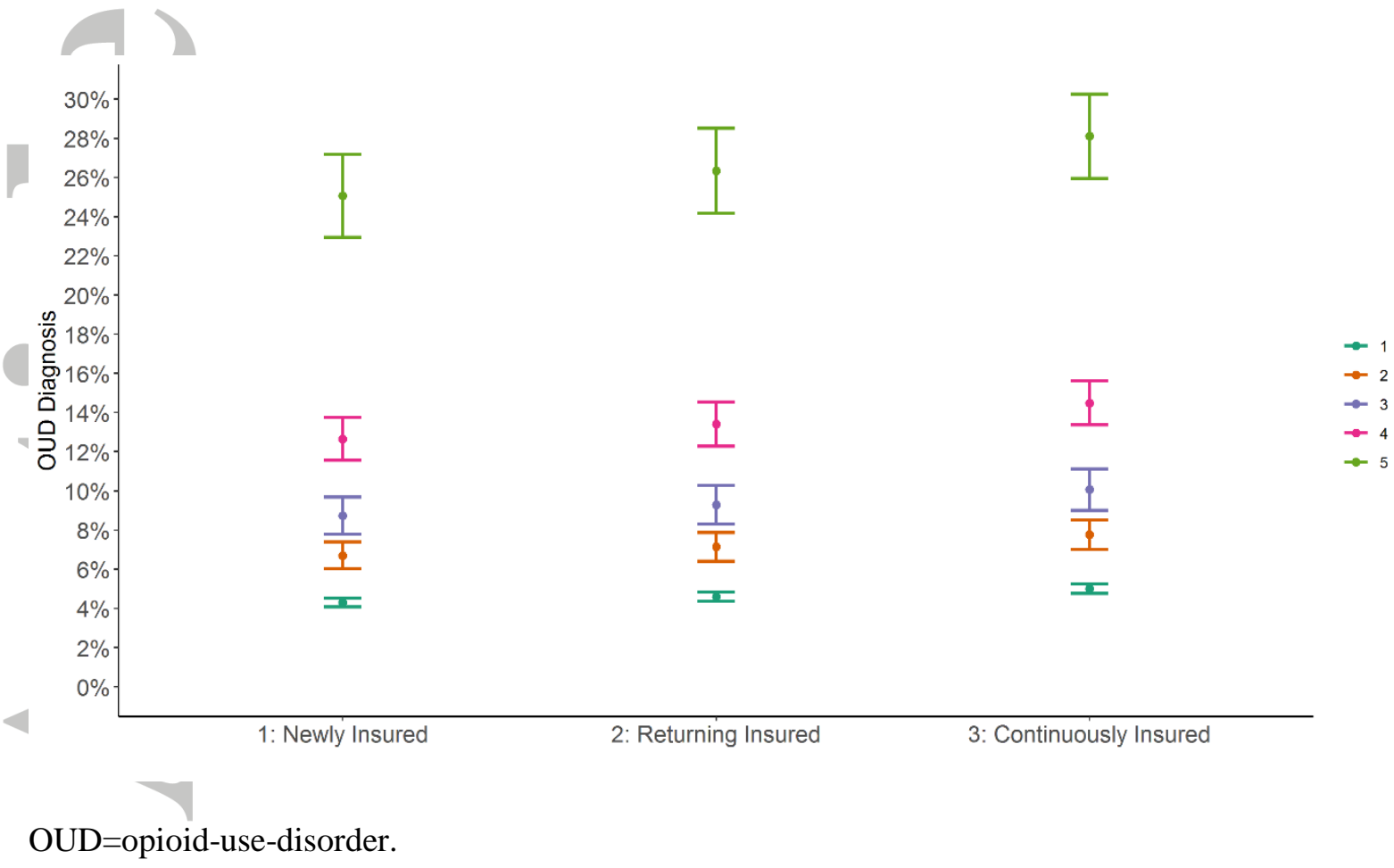

1: Non-chronic ( $\leq 90$ day) use and no high ( $>90$ daily MME) dose, $\mathbf{N}=86,349$

2: Low (1-30 daily MME) dose chronic ( $>90$ day) use and no high dose, $\mathrm{N}=6,649$

3: Non-chronic or low dose chronic use and at least one high dose, $N=4,648$

4: Medium (31-90 daily MME) chronic use and no high dose, $\mathrm{N}=5,207$

5: Medium or high dose chronic use and at least one high dose, $N=2,178$

These estimates and 95\% confidence intervals were produced using binary logistic models incorporating inverse-probability of treatment weights. 


\section{Appendix for}

"Prescription Opioid Use Patterns, Use Disorder Diagnoses, and Addiction Treatment Receipt after the 2014 Medicaid Expansion in Oregon"

The Appendix material contains 4 sections:

Appendix Exhibit A: Sample Exclusions

Appendix Exhibits B1-B4: Definitions

Appendix Exhibit B1: Definition of opioid use disorder (OUD) diagnosis.

Appendix Exhibit B2: Definition of receipt of medication-assisted treatment (MAT) services.

Appendix Exhibit B3: Chronic pain diagnoses.

Appendix Exhibit B4: Definition of opioid overdose event.

Appendix Exhibits C1-C2: Covariate Balance Tables

Appendix Exhibit C1: Characteristics of newly, returning, and continuously insured enrollees (sample with any opioid dispensed).

Appendix Exhibit C2: Characteristics of newly, returning and continuously insured enrollees (sample with OUD diagnosis).

Appendix Exhibits D1-D7: Covariate-Adjusted Parameter Estimates

Appendix Exhibit D1: Binary logistic regression with inverse-probability of treatment weights (IPTW). Marginal predicted probabilities for any opioid prescription filled (full sample) by insurance group.

Appendix Exhibit D2: Binary logistic regression with IPTW. Marginal predicted probabilities for any chronic episode (sample with any opioid dispensed) by insurance group.

Appendix Exhibit D3: Multinomial logistic regression with IPTW. Marginal predicted probabilities for level of chronic opioid use (sample with any opioid dispensed) by insurance group.

Appendix Exhibit D4: Binary logistic regression with IPTW. Marginal predicted probabilities for diagnosis of OUD (full sample) by insurance group.

Appendix Exhibit D5: Cox regression with IPTW. Time to receipt of MAT services after OUD diagnosis by insurance group (sample with OUD diagnosis, excluding patients with MAT receipt before OUD diagnosis).

Appendix Exhibit D6: Binary logistic regression with IPTW. Marginal predicted probabilities for diagnosis of OUD (sample with any opioid dispensed) by insurance group and episode type.

Appendix Exhibit D7: Binary logistic regression with IPTW. Odds ratios for diagnosis of OUD by insurance group (sample with any opioid dispensed). 
Appendix Exhibit A: Sample Exclusions

Adult patients with any Medicaid enrollment in $2014(n=622,513)$

\begin{tabular}{lrr} 
Exclusion Criteria & Frequency & Percent \\
\hline No coverage on 1/1/2014 & 97,005 & 15.6 \\
Other Coverage Gap in Study Period & 167,779 & 27.0 \\
Incomplete data due to dual Medicaid/Medicare coverage & 28,196 & 4.5 \\
Eligibility based on pregnancy & 13,376 & 2.1 \\
Eligibility based on disability & 37,584 & 6.0 \\
Eligibility based on programs not tied to Medicaid & 23,409 & 3.8 \\
Expansion (e.g. TANF, former Foster Care children, dialysis & & \\
patients) & & 3.9 \\
Partial Coverage in 2013* & 24,562 & 0.9 \\
Patients in hospice care or with cancer diagnosis & 5,307 & 36.2 \\
Study Enrollees & 225,295 & \\
\hline
\end{tabular}

*Patients with partial coverage in 2013 were not eligible for the continuously insured group, which required full coverage in 2013 , or the newly or continuously insured groups, which required no coverage in 2013. 
Appendix Exhibits B1-B4: Definitions

Appendix Exhibit B1: Definition of opioid use disorder (OUD) diagnosis.

This is a binary variable indicating whether a subject had a documented diagnosis of OUD during the study period. Classification was based on any of the following ICD-9 or ICD-10 diagnosis codes being present in any claims.

ICD-9: 304.00, 304.01, 304.02, 305.50, 305.51, 305.52.

ICD-10: F11.20, F11.222, F11.259, F11.281, F11.282, F11.288, F11.10, F11.159, F11.181, F11.182, F11.188.

Appendix Exhibit B2: Definition of receipt of medication-assisted treatment (MAT) services. This is a binary variable indicating any claims with any of the following procedure codes or National Drug Codes (NDC).

Procedure Codes

H0020, H0033 with HF or HG modifier, H0016, T1502 with HF or HG modifier, J0571-J0575.

NDCs

Buprenorphine HCl: 00054017613, 00054017713, 00054018813, 00054018913, 00093537856, 00093537956, 00228315303, 00228315603, 00378092393, 00378092493, 50383092493, 50383093093

Buprenorphine-Naloxone: 00228315403, 00228315473, 00228315503, 00228315573, 00093572056, 00093572156, 12496120203, 12496120403, 12496120803, 12496121203, 42291017530, 50383028793, 50383029493, 65162041503, 65162041603

Methylnaltrexone Bromide: 65649055102, 65649055103, 65649055107, 65649055204

Note: Methadone administered for treatment of OUD was paid using CPT codes; thus we classified methadone identified from NDCs as prescribed use for pain. 
Appendix Exhibit B3: Chronic pain diagnoses.

\begin{tabular}{|c|c|c|c|}
\hline Category & Diagnoses included & $\begin{array}{l}\text { ICD-9 } \\
\text { codes }\end{array}$ & ICD-10 codes \\
\hline Migraine & Migraine & 346 & G43 \\
\hline Joint pain & $\begin{array}{l}\text { Diffuse diseases of connective } \\
\text { tissue; arthropathies; rheumatoid } \\
\text { arthritis and other inflammatory } \\
\text { polyarthropathies; polymyalgia } \\
\text { rheumatica; peripheral } \\
\text { enthesopathies; other disorders } \\
\text { of synovium, tendon, and bursa; } \\
\text { disorders of muscle, ligament, } \\
\text { and fascia; other disorders of } \\
\text { soft tissues. }\end{array}$ & $\begin{array}{l}710-714, \\
716-719, \\
725-729\end{array}$ & $\begin{array}{l}\text { M00-M02, M05, } \\
\text { M11-M12, M14- } \\
\text { M19, M23-M25, } \\
\text { M35-M36, M60- } \\
\text { M62, M65-M67, } \\
\text { M70-M72, M75- } \\
\text { M77 }\end{array}$ \\
\hline Osteoarthritis & $\begin{array}{l}\text { Osteoarthritis and allied } \\
\text { disorders; ankylosing } \\
\text { spondylitis and other } \\
\text { inflammatory spondylopathies. }\end{array}$ & 715,720 & $\begin{array}{l}\text { M15-M19, M45- } \\
\text { M46 }\end{array}$ \\
\hline Back and spinal pain & $\begin{array}{l}\text { Spondylosis and allied } \\
\text { disorders; intervertebral disc } \\
\text { disorders; other disorders of } \\
\text { cervical region; other and } \\
\text { unspecified disorders of back. }\end{array}$ & $721-724$ & $\begin{array}{l}\text { M43, M47-M48, } \\
\text { M50-M54 }\end{array}$ \\
\hline $\begin{array}{l}\text { General chronic } \\
\text { pain }\end{array}$ & $\begin{array}{l}\text { Tension headache; other pain } \\
\text { disorders related to } \\
\text { psychological factors; chronic } \\
\text { pain due to trauma; chronic } \\
\text { post-thoracotomy pain; other } \\
\text { chronic postoperative pain; } \\
\text { other chronic pain; chronic pain } \\
\text { syndrome }\end{array}$ & $\begin{array}{l}30781, \\
30789, \\
33821, \\
33822, \\
33828, \\
33829, \\
78071\end{array}$ & $\begin{array}{l}\text { G44209, F4542, } \\
\text { G8921, G8922, } \\
\text { G8928, G8929, } \\
\text { G893, G894 }\end{array}$ \\
\hline
\end{tabular}


Appendix Exhibit B4: Definition of opioid overdose event.

\begin{tabular}{|c|c|c|c|}
\hline & $\begin{array}{l}\text { Contributing cause } \\
\text { (ICD-10) }\end{array}$ & Diagnosis (ICD-9) & $\begin{array}{l}\text { External Cause of } \\
\text { Injury (ICD-9) }\end{array}$ \\
\hline $\begin{array}{l}\text { All opioid } \\
\text { poisoning (illicit } \\
\text { and prescription) }\end{array}$ & $\begin{array}{l}\text { T400 (Poisoning by } \\
\text { Opium), T401 } \\
\text { (Poisoning by Heroin), } \\
\text { T402 (Poisoning by } \\
\text { Other Opioids), T403 } \\
\text { (Poisoning by } \\
\text { Methadone), T404 } \\
\text { (Poisoning by } \\
\text { Synthetic Narcotics) }\end{array}$ & $\begin{array}{l}96500 \text { (Poisoning by } \\
\text { Opium), } 96501 \\
\text { (Poisoning by } \\
\text { Heroin), } 96502 \\
\text { (Poisoning by } \\
\text { Methadone), } 96509 \\
\text { (Poisoning by Other } \\
\text { Opiates) }\end{array}$ & $\begin{array}{l}\text { E8500 (Accidental } \\
\text { Poisoning by Heroin), } \\
\text { E8501 (Accidental } \\
\text { Poisoning by } \\
\text { Methadone), E8502 } \\
\text { (Accidental Poisoning } \\
\text { by Other Opiates) }\end{array}$ \\
\hline
\end{tabular}

These codes (ICD-10 Contributing Cause or ICD-9 Diagnosis or External Cause of Injury) capture both 1) non-fatal overdoses resulting in hospitalization or other medical care and 2) fatal overdoses resulting in hospitalization or other medical care.

Below is a table of raw (unadjusted) counts for patients with $\geq 1$ opioid overdose event for all three samples by insurance group.

\begin{tabular}{|l|l|l|l|l|l|l|}
\hline & \multicolumn{2}{|l|}{ Full sample } & \multicolumn{2}{l|}{$\begin{array}{l}\text { Sample with any } \\
\text { opioid }\end{array}$} & \multicolumn{2}{l|}{$\begin{array}{l}\text { Sample with OUD } \\
\text { diagnosis }\end{array}$} \\
\hline Insurance Group & $\mathrm{N}$ & $\begin{array}{l}\mathrm{N}(\%) \\
\text { opioid } \\
\text { overdose }\end{array}$ & $\mathrm{N}$ & $\begin{array}{l}\mathrm{N}(\%) \\
\text { opioid } \\
\text { overdose }\end{array}$ & $\mathrm{N}$ & $\begin{array}{l}\mathrm{N}(\%) \\
\text { opioid } \\
\text { overdose }\end{array}$ \\
\hline Newly insured & 108,501 & $244(0.23 \%)$ & 40,614 & $\begin{array}{l}157 \\
(0.39 \%)\end{array}$ & 2,941 & $\begin{array}{l}147 \\
(5.00 \%)\end{array}$ \\
\hline $\begin{array}{l}\text { Returning } \\
\text { insured }\end{array}$ & 59,811 & $218(0.37 \%)$ & 30,164 & $\begin{array}{l}156 \\
(0.52 \%)\end{array}$ & 2,673 & $\begin{array}{l}133 \\
(4.98 \%)\end{array}$ \\
\hline $\begin{array}{l}\text { Continuously } \\
\text { insured }\end{array}$ & 56,983 & $149(0.26 \%)$ & 34,253 & $\begin{array}{l}131 \\
(0.38 \%)\end{array}$ & 3,343 & $\begin{array}{l}88 \\
(2.53 \%)\end{array}$ \\
\hline
\end{tabular}

For adjusted estimates, see Appendix D5. 
Appendix Exhibits C1-C2: Covariate Balance Tables

Appendix Exhibit C1: Characteristics of newly, returning and continuously insured enrollees (sample with any opioid dispensed).

\begin{tabular}{|c|c|c|c|c|c|c|c|c|}
\hline & \multicolumn{4}{|c|}{ Unweighted Sample, $\%$} & \multicolumn{4}{|c|}{ Inverse Propensity Weighted Sample, \% } \\
\hline & $\begin{array}{l}\text { Newly } \\
\text { Insured }\end{array}$ & $\begin{array}{l}\text { Returning } \\
\text { Insured }\end{array}$ & $\begin{array}{c}\text { Cont. } \\
\text { Insured }\end{array}$ & $\begin{array}{c}\text { Max }^{1} \\
\text { ASMD }\end{array}$ & $\begin{array}{l}\text { Newly } \\
\text { Insured }\end{array}$ & $\begin{array}{c}\text { Returning } \\
\text { Insured }\end{array}$ & $\begin{array}{c}\text { Cont. } \\
\text { Insured }\end{array}$ & $\begin{array}{c}\operatorname{Max}^{1} \\
\text { ASMD }\end{array}$ \\
\hline Total N|ESS & 40,614 & 30,164 & 34,253 & & 31,332 & 27,607 & 25,832 & \\
\hline \multicolumn{9}{|l|}{ Age group } \\
\hline $19-29$ & 17.8 & 27.9 & 30.7 & 0.2828 & 24.8 & 24.9 & 24.9 & 0.0022 \\
\hline $30-39$ & 21.7 & 26.8 & 30.4 & 0.1939 & 26.0 & 26.0 & 26.0 & 0.0012 \\
\hline $40-64$ & 60.5 & 45.2 & 38.9 & 0.439 & 49.2 & 49.1 & 49.1 & 0.0031 \\
\hline Female & 46.7 & 57.1 & 71.5 & 0.5188 & 57.6 & 57.8 & 57.9 & 0.0059 \\
\hline \multicolumn{9}{|l|}{ Race/Ethnicity } \\
\hline Hispanic & 13.6 & 12.0 & 7.5 & 0.2092 & 11.1 & 11.2 & 11.1 & 0.0008 \\
\hline Non-Hisp. Non-White & 8.3 & 9.2 & 7.9 & 0.0468 & 8.4 & 8.4 & 8.3 & 0.0042 \\
\hline Non-Hisp. White & 60.3 & 72.8 & 77.7 & 0.4042 & 69.7 & 69.8 & 70.1 & 0.0093 \\
\hline Non-Hisp. Unknown & 17.8 & 6.0 & 7.0 & 0.4757 & 10.8 & 10.6 & 10.5 & 0.0115 \\
\hline Rural setting ${ }^{2}$ & 40.1 & 42.7 & 42.2 & 0.0533 & 41.5 & 41.5 & 41.5 & 0.0007 \\
\hline \multicolumn{9}{|l|}{ ZCTA ${ }^{3}$ Unemployment $\%$} \\
\hline $0-8.09$ & 26.2 & 21.2 & 20.1 & 0.1521 & 22.8 & 22.7 & 22.6 & 0.0048 \\
\hline $8.09-9.58$ & 24.7 & 23.7 & 23.5 & 0.0278 & 24.1 & 24.1 & 24.0 & 0.0031 \\
\hline $9.58-11.56$ & 25.1 & 26.8 & 27.9 & 0.0628 & 26.5 & 26.5 & 26.6 & 0.0022 \\
\hline $11.56-38.84$ & 23.8 & 28.2 & 28.4 & 0.1014 & 26.6 & 26.5 & 26.8 & 0.0057 \\
\hline Unknown & 0.1 & 0.1 & 0.1 & 0.014 & 0.1 & 0.1 & 0.0 & 0.0084 \\
\hline \multicolumn{9}{|l|}{ ZCTA ${ }^{3}$ Poverty $\%$} \\
\hline $0-13.0$ & 26.5 & 22.2 & 22.3 & 0.1026 & 24.0 & 24.0 & 23.8 & 0.0039 \\
\hline $13.0-17.0$ & 25.6 & 25.0 & 24.0 & 0.0376 & 24.8 & 24.8 & 24.8 & 0.0005 \\
\hline $17.0-22.6$ & 25.8 & 26.9 & 28.1 & 0.0505 & 26.8 & 26.9 & 26.9 & 0.0026 \\
\hline $22.6-100$ & 22.0 & 25.8 & 25.7 & 0.0854 & 24.4 & 24.3 & 24.4 & 0.0018 \\
\hline Unknown & 0.1 & 0.1 & 0.0 & 0.0174 & 0.1 & 0.1 & 0.0 & 0.0074 \\
\hline \multicolumn{9}{|l|}{ Co-Morbidity Index 4} \\
\hline 0 & 23.9 & 21.5 & 19.6 & 0.1073 & 21.8 & 21.8 & 21.8 & 0.0023 \\
\hline 1 to 2 & 22.2 & 17.6 & 20.3 & 0.1151 & 20.2 & 20.3 & 20.3 & 0.0025 \\
\hline 3 to 4 & 26.9 & 30.5 & 28.9 & 0.0798 & 28.5 & 28.6 & 28.6 & 0.002 \\
\hline 5 to 6 & 15.7 & 17.6 & 17.5 & 0.0484 & 16.8 & 16.8 & 16.8 & 0.0015 \\
\hline $7+$ & 11.4 & 12.8 & 13.7 & 0.0693 & 12.6 & 12.6 & 12.5 & 0.0018 \\
\hline Migraine & 8.0 & 10.1 & 14.3 & 0.2041 & 10.7 & 10.6 & 10.7 & 0.0012 \\
\hline Joint Pain & 58.9 & 59.4 & 62.1 & 0.0668 & 60.2 & 60.1 & 60.1 & 0.0033 \\
\hline Osteoarthritis & 17.0 & 13.7 & 14.2 & 0.0918 & 15.1 & 15.0 & 15.0 & 0.0022 \\
\hline Back Pain & 43.8 & 45.8 & 51.6 & 0.1560 & 46.8 & 46.9 & 46.9 & 0.0025 \\
\hline
\end{tabular}


${ }^{1}$ Maximum absolute standardized mean difference (ASMD) across all pairwise comparisons for each level of pretreatment covariate.

${ }^{2}$ Rural defined by zip codes ten or more miles from the centroid of a population center of 40,000 people or more (Oregon Office of Rural Health).

${ }^{3}$ ZIP Code Tabulation Areas.

${ }^{4}$ Level of co-morbidity assessed by the enhanced Charlson comorbidity index.
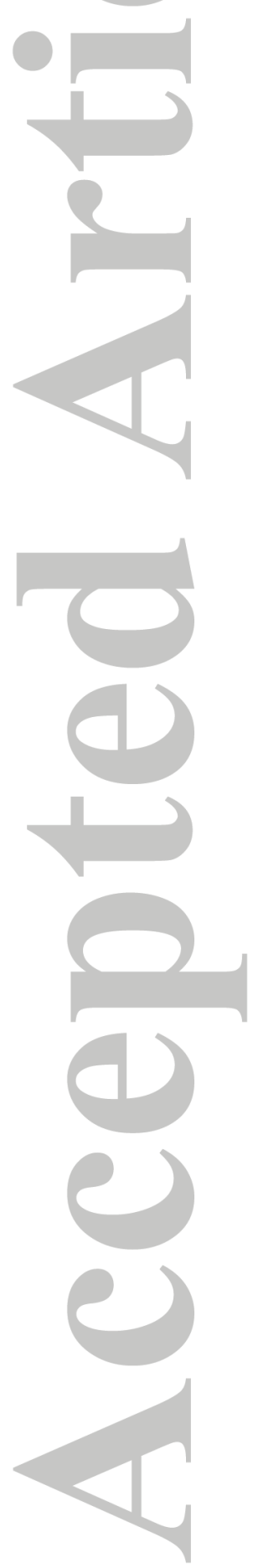
Appendix Exhibit C2: Characteristics of newly, returning and continuously insured enrollees (sample with OUD diagnosis).

\begin{tabular}{|c|c|c|c|c|c|c|c|c|}
\hline & \multicolumn{4}{|c|}{ Unweighted Sample, \% } & \multicolumn{4}{|c|}{ Inverse Propensity Weighted Sample, \% } \\
\hline & $\begin{array}{l}\text { Newly } \\
\text { Insured }\end{array}$ & $\begin{array}{l}\text { Returning } \\
\text { Insured }\end{array}$ & $\begin{array}{l}\text { Cont. } \\
\text { Insured }\end{array}$ & $\begin{array}{c}\operatorname{Max}^{1} \\
\text { ASMD }\end{array}$ & $\begin{array}{l}\text { Newly } \\
\text { Insured }\end{array}$ & $\begin{array}{l}\text { Returning } \\
\text { Insured }\end{array}$ & $\begin{array}{l}\text { Cont. } \\
\text { Insured }\end{array}$ & $\begin{array}{l}\text { Max }^{1} \\
\text { ASMD }\end{array}$ \\
\hline Total N|ESS & 2,941 & 2,673 & 3,343 & & 2,327 & 2,515 & 2,550 & \\
\hline \multicolumn{9}{|l|}{ Age group } \\
\hline $19-29$ & 36.0 & 36.7 & 28.4 & 0.176 & 33.7 & 33.5 & 32.9 & 0.0176 \\
\hline $30-39$ & 27.9 & 27.9 & 37.1 & 0.1953 & 31.0 & 31.0 & 31.7 & 0.0135 \\
\hline $40-64$ & 36.1 & 35.4 & 34.5 & 0.0346 & 35.2 & 35.4 & 35.4 & 0.0041 \\
\hline Female & 32.2 & 44.8 & 66.9 & 0.702 & 48.0 & 48.9 & 49.7 & 0.0327 \\
\hline \multicolumn{9}{|l|}{ Race/Ethnicity } \\
\hline Hispanic & 10.7 & 9.2 & 3.8 & 0.2854 & 7.7 & 7.6 & 7.0 & 0.0264 \\
\hline Non-Hisp. Non-White & 6.5 & 8.1 & 6.0 & 0.0814 & 6.7 & 6.8 & 6.6 & 0.0082 \\
\hline Non-Hisp. White & 68.0 & 76.8 & 82.3 & 0.357 & 76.3 & 76.7 & 77.7 & 0.0334 \\
\hline Non-Hisp. Unknown & 14.8 & 6.0 & 7.8 & 0.3448 & 9.3 & 9.0 & 8.7 & 0.0229 \\
\hline Rural setting $^{2}$ & 28.6 & 30.4 & 30.7 & 0.0456 & 29.8 & 30.0 & 29.8 & 0.0047 \\
\hline \multicolumn{9}{|l|}{ ZCTA ${ }^{3}$ Unemployment $\%$} \\
\hline $0-8.09$ & 27.2 & 21.5 & 20.7 & 0.1603 & 23.3 & 23.0 & 22.5 & 0.0206 \\
\hline $8.09-9.58$ & 26.9 & 27.0 & 25.3 & 0.0388 & 26.4 & 26.5 & 26.7 & 0.0073 \\
\hline $9.58-11.56$ & 25.5 & 26.5 & 27.3 & 0.0409 & 26.6 & 26.3 & 26.4 & 0.0057 \\
\hline $11.56-38.84$ & 20.3 & 24.7 & 26.5 & 0.1421 & 23.5 & 23.9 & 24.2 & 0.0158 \\
\hline Unknown & 0.2 & 0.3 & 0.3 & 0.0243 & 0.3 & 0.3 & 0.3 & 0.0031 \\
\hline \multicolumn{9}{|l|}{ ZCTA ${ }^{3}$ Poverty $\%$} \\
\hline $0-13.0$ & 28.2 & 24.7 & 23.0 & 0.1225 & 25.2 & 25.4 & 25.2 & 0.0046 \\
\hline $13.0-17.0$ & 24.5 & 22.7 & 20.8 & 0.0889 & 22.5 & 22.7 & 22.3 & 0.0099 \\
\hline $17.0-22.6$ & 25.6 & 25.7 & 28.3 & 0.0599 & 26.6 & 26.5 & 26.5 & 0.0043 \\
\hline $22.6-100$ & 21.5 & 26.5 & 27.7 & 0.1382 & 25.4 & 25.2 & 25.9 & 0.0146 \\
\hline Unknown & 0.2 & 0.3 & 0.3 & 0.0243 & 0.3 & 0.3 & 0.3 & 0.0031 \\
\hline \multicolumn{9}{|l|}{ Co-Morbidity Index ${ }^{4}$} \\
\hline 0 & 0.5 & 0.2 & 0.1 & 0.0885 & 0.3 & 0.2 & 0.3 & 0.023 \\
\hline 1 to 2 & 0.4 & 0.3 & 0.1 & 0.0483 & 0.2 & 0.2 & 0.1 & 0.0328 \\
\hline 3 to 4 & 44.7 & 41.4 & 40.8 & 0.0789 & 42.4 & 42.5 & 42.4 & 0.0019 \\
\hline 5 to 6 & 29.6 & 31.0 & 29.5 & 0.0323 & 29.6 & 29.9 & 29.9 & 0.0064 \\
\hline $7+$ & 24.8 & 27.1 & 29.4 & 0.1025 & 27.5 & 27.2 & 27.4 & 0.0062 \\
\hline Migraine & 6.8 & 9.9 & 13.6 & 0.2234 & 9.9 & 10.0 & 10.4 & 0.0162 \\
\hline Joint Pain & 52.8 & 58.0 & 60.6 & 0.1583 & 57.2 & 57.2 & 56.8 & 0.0097 \\
\hline Osteoarthritis & 12.6 & 12.3 & 14.1 & 0.052 & 13.0 & 12.7 & 13.0 & 0.0096 \\
\hline Back Pain & 42.9 & 45.1 & 53.9 & 0.2188 & 47.1 & 47.3 & 47.9 & 0.0163 \\
\hline
\end{tabular}


${ }^{1}$ Maximum absolute standardized mean difference (ASMD) across all pairwise comparisons for each level of pretreatment covariate.

${ }^{2}$ Rural defined by zip codes ten or more miles from the centroid of a population center of 40,000 people or more (Oregon Office of Rural Health).

${ }^{3}$ ZIP Code Tabulation Areas.

${ }^{4}$ Level of co-morbidity assessed by the enhanced Charlson comorbidity index.
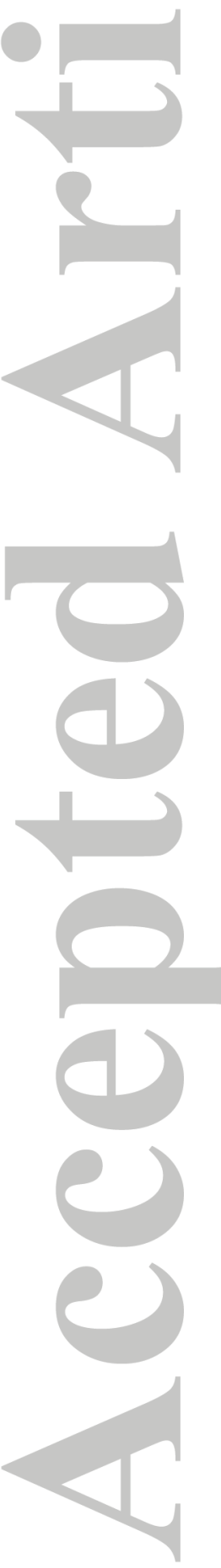
Appendix Exhibits D1-D8: Covariate-Adjusted Parameter Estimates

Appendix Exhibit D1: Binary logistic regression with IPTW. Marginal predicted probabilities for any opioid prescription filled (full sample) by insurance group.

Number of observations: 225,295

Dependent variable: Any opioid prescription filled

Independent variable: Insurance group

Adjusted predictions

\begin{tabular}{|l|l|l|l|}
\hline Insurance group & Estimate & Standard Error & 95\% Confidence Interval \\
\hline Newly insured & 0.4234 & 0.0017 & $0.4200-0.4267$ \\
\hline Returning insured & 0.4925 & 0.0023 & $0.4880-0.4970$ \\
\hline Continuously insured & 0.5250 & 0.0027 & $0.5197-0.5303$ \\
\hline
\end{tabular}

Appendix Exhibit D2: Binary logistic regression with IPTW. Marginal predicted probabilities for any chronic episode (sample with any opioid dispensed) by insurance group.

Number of observations: 105,031

Dependent variable: Any chronic episode

Independent variable: Insurance group

Additional covariate: Number of episodes

Adjusted predictions

\begin{tabular}{|l|l|l|l|}
\hline Insurance group & Estimate & Standard Error & 95\% Confidence Interval \\
\hline Newly insured & 0.1276 & 0.0019 & $0.1240-0.1313$ \\
\hline Returning insured & 0.1190 & 0.0019 & $0.1152-0.1227$ \\
\hline Continuously insured & 0.1581 & 0.0021 & $0.1540-0.1621$ \\
\hline
\end{tabular}


Appendix Exhibit D3: Multinomial logistic regression with IPTW. Marginal predicted probabilities for level of chronic opioid use (sample with any opioid dispensed) by insurance group.

Number of observations: 105,031

Dependent variable: Level of chronic opioid use (no chronic and low/medium acute, no chronic and high acute, low chronic, medium chronic, and high chronic)

Independent variables: Insurance group

Additional covariate: Number of episodes

Adjusted predictions

\begin{tabular}{|c|c|c|c|c|}
\hline Insurance group & $\begin{array}{l}\text { Level of chronic } \\
\text { opioid use }\end{array}$ & Estimate & $\begin{array}{l}\text { Standard } \\
\text { Error }\end{array}$ & $\begin{array}{l}\text { 95\% Confidence } \\
\text { Interval }\end{array}$ \\
\hline Newly insured & $\begin{array}{l}\text { No chronic, } \\
\text { low/medium acute }(\leq 90 \\
\text { MME) }\end{array}$ & 0.8265 & 0.0021 & $0.8224-0.8306$ \\
\hline Returning insured & $\begin{array}{l}\text { No chronic, } \\
\text { low/medium acute }(\leq 90 \\
\text { MME) }\end{array}$ & 0.8411 & 0.0022 & $0.8369-0.8453$ \\
\hline Continuously insured & $\begin{array}{l}\text { No chronic, } \\
\text { low/medium acute }(\leq 90 \\
\text { MME) }\end{array}$ & 0.8004 & 0.0023 & $0.7959-0.8050$ \\
\hline Newly insured & $\begin{array}{l}\text { No chronic, high acute } \\
\text { (>90 MME) }\end{array}$ & 0.0459 & 0.0012 & $0.0435-0.0482$ \\
\hline Returning insured & $\begin{array}{l}\text { No chronic, high acute } \\
\text { (>90 MME) }\end{array}$ & 0.0399 & 0.0012 & $0.0376-0.0422$ \\
\hline Continuously insured & $\begin{array}{l}\text { No chronic, high acute } \\
\text { (>90 MME) }\end{array}$ & 0.0415 & 0.0012 & $0.0390-0.0439$ \\
\hline Newly insured & $\begin{array}{l}\text { Low chronic } \\
\text { (1-30 MME) }\end{array}$ & 0.0633 & 0.0014 & $0.0605-0.0660$ \\
\hline Returning insured & $\begin{array}{l}\text { Low chronic } \\
\text { (1-30 MME) }\end{array}$ & 0.0590 & 0.0014 & $0.0563-0.0618$ \\
\hline Continuously insured & $\begin{array}{l}\text { Low chronic } \\
\text { (1-30 MME) }\end{array}$ & 0.0719 & 0.0015 & $0.0690-0.0748$ \\
\hline Newly insured & $\begin{array}{l}\text { Medium chronic (31-90 } \\
\text { MME) }\end{array}$ & 0.0477 & 0.0012 & 0.0453-0.0501 \\
\hline Returning insured & $\begin{array}{l}\text { Medium chronic (31-90 } \\
\text { MME) }\end{array}$ & 0.0459 & 0.0013 & $0.0434-0.0484$ \\
\hline Continuously insured & $\begin{array}{l}\text { Medium chronic (31-90 } \\
\text { MME) }\end{array}$ & 0.0626 & 0.0014 & $0.0598-0.0653$ \\
\hline Newly insured & $\begin{array}{l}\text { High chronic ( }>90 \\
\text { MME) }\end{array}$ & 0.0167 & 0.0007 & $0.0153-0.0181$ \\
\hline Returning insured & $\begin{array}{l}\text { High chronic (>90 } \\
\text { MME) }\end{array}$ & 0.0141 & 0.0007 & $0.0127-0.0154$ \\
\hline Continuously insured & $\begin{array}{l}\text { High chronic (>90 } \\
\text { MME) }\end{array}$ & 0.0236 & 0.0009 & $0.0220-0.0253$ \\
\hline
\end{tabular}


Appendix Exhibit D4: Binary logistic regression with IPTW. Marginal predicted probabilities for diagnosis of OUD (full sample) by insurance group.

Number of observations: 225,295

Dependent variable: Diagnosis of OUD

Independent variable: Insurance group

Adjusted predictions

\begin{tabular}{|l|l|l|l|}
\hline Insurance group & Estimate & Standard Error & 95\% Confidence Interval \\
\hline Newly insured & 0.0356 & 0.0007 & $0.0342-0.0370$ \\
\hline Returning insured & 0.0392 & 0.0008 & $0.0377-0.0407$ \\
\hline Continuously insured & 0.0470 & 0.0009 & $0.0452-0.0489$ \\
\hline
\end{tabular}

Appendix Exhibit D5: Cox Regression with IPTW. Time to receipt of MAT services after OUD diagnosis by insurance group (sample with OUD diagnosis, excluding patients with MAT receipt before OUD diagnosis).

$164(3.7 \%)$ of 4,446 patients who received MAT did not have any diagnosis of OUD during the study period. Because we were unable to determine when, if ever, they were diagnosed with OUD, these patients were not included in the time-to-event analysis.

$320(3.6 \%)$ of 8,957 patients diagnosed with OUD in our sample received MAT before their earliest known diagnoses of OUD. These patients were excluded from the time to event analysis. In the weighted sample of patients with OUD, $2.9 \%$ of the newly insured, $2.5 \%$ of the returning insured, and $5.1 \%$ of the continuously insured were excluded from the MAT analysis for this reason.

Number of observations: 8,637

Dependent variable: Time from OUD diagnosis to MAT receipt

Independent variable: Insurance group

Adjusted hazard ratio estimates

\begin{tabular}{|l|l|l|l|}
\hline Insurance group & Estimate & Standard Error & 95\% Confidence Interval \\
\hline $\begin{array}{l}\text { Newly insured (REF: } \\
\text { Continuously insured) }\end{array}$ & 0.5711 & 0.0222 & $0.5292-0.6163$ \\
\hline $\begin{array}{l}\text { Returning insured (REF: } \\
\text { Continuously insured }\end{array}$ & 0.6022 & 0.0224 & $0.5598-0.6477$ \\
\hline
\end{tabular}

This article is protected by copyright. All rights reserved. 
Appendix Exhibit D6: Binary logistic regression with IPTW. Marginal predicted probabilities for diagnosis of OUD (sample with any opioid dispensed) by insurance group and episode type.

Number of observations: 105,031

Dependent variable: Diagnosis of OUD

Independent variables: Insurance group, episode type

Additional covariate: Number of episodes

Episode type:

1: No chronic opioid use and no high dose episode

2: Low chronic opioid use and no high dose episode

3: No chronic or low chronic opioid use; $\geq 1$ high dose episode

4: Medium chronic use and no high dose episode

5: Medium or high chronic opioid use; $\geq 1$ high dose episode

$\underline{\text { Adjusted predictions }}$

\begin{tabular}{|l|l|l|l|}
\hline Insurance group/Episode type & Estimate & Standard Error & $\begin{array}{l}\text { 95\% Confidence } \\
\text { Interval }\end{array}$ \\
\hline Newly insured / 1 & 0.0431 & 0.0012 & $0.04076-0.0454$ \\
\hline Returning insured / 1 & 0.0460 & 0.0012 & $0.04368-0.04823$ \\
\hline Continuously insured / 1 & 0.0500 & 0.0013 & $0.04755-0.05254$ \\
\hline Newly insured / 2 & 0.0671 & 0.0035 & $0.06016-0.07398$ \\
\hline Returning insured / 2 & 0.0714 & 0.0037 & $0.06417-0.07866$ \\
\hline Continuously insured / 2 & 0.0776 & 0.0038 & $0.07013-0.08507$ \\
\hline Newly insured / 3 & 0.0874 & 0.0048 & $0.07791-0.0968$ \\
\hline Returning insured / 3 & 0.0929 & 0.0051 & $0.0830-0.1028$ \\
\hline Continuously insured / 3 & 0.1007 & 0.0054 & $0.0901-0.1113$ \\
\hline Newly insured / 4 & 0.1265 & 0.0056 & $0.1156-0.1374$ \\
\hline Returning insured / 4 & 0.1341 & 0.0058 & $0.1229-0.1454$ \\
\hline Continuously insured / 4 & 0.1449 & 0.0057 & $0.1337-0.1561$ \\
\hline Newly insured / 5 & 0.2506 & 0.0108 & $0.2295-0.2717$ \\
\hline Returning insured / 5 & 0.2634 & 0.0111 & $0.2417-0.2851$ \\
\hline Continuously insured / 5 & 0.2811 & 0.0110 & $0.2595-0.3026$ \\
\hline
\end{tabular}

This article is protected by copyright. All rights reserved. 
Appendix Exhibit D7: Binary logistic regression with IPTW. Odds ratios for diagnosis of OUD (sample with any opioid dispensed) by insurance group.

Number of observations: 105,031

Dependent variable: Diagnosis of OUD

Independent variable: Insurance group

Additional covariates: Episode type, number of episodes

$\underline{\text { Adjusted Odds Ratios }}$

\begin{tabular}{|l|l|l|l|}
\hline Insurance group & Estimate & Standard Error & 95\% Confidence Interval \\
\hline $\begin{array}{l}\text { Newly insured (REF: } \\
\text { Continuously insured) }\end{array}$ & 0.8544 & 0.0310 & $0.7957-0.9175$ \\
\hline $\begin{array}{l}\text { Returning insured (REF: } \\
\text { Continuously insured }\end{array}$ & 0.9141 & 0.0318 & $0.8538-0.9785$ \\
\hline
\end{tabular}

Appendix Exhibit D8: Binary logistic regression with IPTW. Marginal predicted probabilities for any opioid overdose event, fatal or non-fatal, resulting in hospitalization or visit (full sample) by insurance status.

Number of observations: 225,295

Dependent variable: Any opioid overdose event.

Independent variable: Insurance group.

Adjusted predictions

\begin{tabular}{|l|l|l|l|}
\hline Insurance group & Estimate & Standard Error & 95\% Confidence Interval \\
\hline Newly insured & 0.0031 & 0.0002 & $0.0027-0.0035$ \\
\hline Returning insured & 0.0032 & 0.0002 & $0.0024-0.0036$ \\
\hline Continuously insured & 0.0019 & 0.0002 & $0.0016-0.0023$ \\
\hline
\end{tabular}

